\title{
Is there a legal obligation to reintroduce animal species into their former habitats?
}

\author{
P. A. Rees
}

\begin{abstract}
Species reintroduction programmes are an important feature of global conservation efforts. There is evidence within the texts of some international and European laws of legal obligations to reintroduce species to their former habitats. However, these obligations are inconsistent between legal instruments, and it is not at all clear exactly what it is they are legislating to recreate. In particular, definitions of native species are either absent from the law or unclear, especially in an historical context. Attempts to reintroduce some predators have been met with legal challenges, and so it is essential that conservation authorities have a clear
\end{abstract}

mission in their reintroduction activities and that this mission is reflected in their national law. Successful reintroductions will be achieved only with public support, and this is more likely where clear objectives have been established after public consultation. Conservation authorities undertaking reintroduction projects should use the legal system and the international commitments made by their governments to validate their efforts.

Keywords beavers, law, reintroduction, wolves.

\section{Introduction}

Within the next few years it is probable that the European beaver Castor fiber will return to Scotland. Brown bears Ursus arctos have been reintroduced into the Pyrenees, and the Norwegian government is currently attempting to re-establish a population of grey wolves Canis lupus. But are these reintroduction programmes undertaken for the benefit of the species concerned or for the benefit of humans, or are we merely fulfilling our legal obligations to wildlife?

\section{The search for legal obligations}

There are three levels at which legal obligations to reintroduce species may have been created: the international level, the European level and the national level. At the national level, this paper primarily considers UK and US law. The Convention on the Conservation of European Wildlife and Natural Habitats (1979), the Berne Convention, was the first wildlife treaty to encourage its Parties to reintroduce native species as a method of conservation. Although the use of this method was recognized by Lyster (1985) he did not discuss the legal and practical difficulties of this approach.

Under Article 11(2) of the convention the Contracting Parties undertake:

P. A. Rees School of Environment and Life Sciences, Allerton Building, University of Salford, Salford M6 6PU, UK.

E-mail: p.a.rees@salford.ac.uk

Revised manuscript accepted for publication 24 January 2001 (a) to encourage the reintroduction of native species of wild flora and fauna when this would contribute to the conservation of an endangered species, provided that a study is first made in the light of the experiences of other Contracting Parties to establish that such reintroductions would be effective and acceptable;

(b) to strictly control the introduction of non-native species.

More recently, the Convention on Biological Diversity 1992 has reaffirmed an international commitment to the recovery of species. The preamble to the treaty states that:

...the fundamental requirement for the conservation of biological diversity is the in-situ conservation of ecosystems and natural habitats and the maintenance and recovery of viable populations of species in their natural surroundings.

Article $8(\mathrm{~d})$ creates an obligation upon Contracting Parties to:

Promote the protection of ecosystems, natural habitats and the maintenance of viable populations of species in natural surroundings;

and Article 8(f) creates a further obligation to:

...promote the recovery of threatened species...

Article 8(h) requires that Contracting Parties:

Prevent the introduction of, control or eradicate those alien species which threaten ecosystems, habitats or species.

Article $9(\mathrm{c})$ creates an obligation to reintroduce threatened species, requiring that: 
Each Contracting Party shall, as far as possible and as appropriate, and predominantly for the purpose of complementing in-situ measures:

(c) Adopt measures for the recovery and rehabilitation of threatened species and for their reintroduction into their natural habitats under appropriate conditions.

The obligations to reintroduce species, created by the Berne Convention and the Biodiversity Convention, are not reflected in European law. By the time Article 11(2) of the Berne Convention was translated into European law the meaning had been altered. Council Directive 92/ 43/EEC of 21 May 1992 on the Conservation of Natural Habitats and of Wild Fauna and Flora requires, under Article 22, that Members States shall:

(a) study (sic) the desirability of re-introducing species in Annex IV, that are native to their territory where this might contribute to their conservation, provided that an investigation, also taking into account experience in other Member States or elsewhere, has established that such re-introduction contributes effectively to re-establishing these species at a favourable conservation status and that it takes place only after proper consultation of the public concerned.

The original obligation to encourage the reintroduction of native species has here been replaced by an obligation simply to study the desirability of reintroducing them. No mention is made in the directive of any specific obligation to reintroduce, and this omission would seem to prevent the directive from fulfilling the requirements of the Berne Convention.

The Directive on the Conservation of Wild Birds (Council Directive 79/409/EEC, 2 April 1979) does not specifically refer to the need either to study the feasibility of or implement reintroduction programmes, but it does appear to accept that such programmes are necessary to bird conservation. Article 9,1(b) allows derogations from Articles 5, 6, 7 and 8 (which prohibit inter alia the taking of birds and eggs):

for the purposes of repopulation, of reintroduction and for the breeding necessary for these purposes.

The use of reintroductions as a conservation tool is also considered in other regional instruments such as the Protocol for the implementation of the Alpine Convention in the Field of Nature Protection and Landscape Conservation (adopted in Chambéry on 20 December 1994) and the Protocol concerning Specially Protected Areas and Biodiversity in the Mediterranean (adopted in Barcelona on 10 June 1995).

Stanley Price et al. (1996) of the IUCN/SSC Reintroduction Specialist Group have noted that many countries have no regulations relating specifically to the release and re-establishment of native species. However, they acknowledged that there had been a recent increase in legislation relating to reintroduction.

In Britain the Wildlife and Countryside Act 1981 makes no specific provisions for the encouragement of reintroductions, but it does strictly control releases to the wild. Section 14 (1) of the Act makes it an offence to introduce non-native species, specifically:

...if any person releases or allows to escape into the wild any animal which -

(a) is of a kind which is not ordinarily resident in and is not a regular visitor to Great Britain in a wild state...he shall be guilty of an offence.

Schedule 9 to the act lists animals and plants that are established in the wild. This list includes species that have been introduced in the past and that cannot be released into the wild without a licence from the appropriate authority (WCA, 1981 s.16(4)(c)). Under Section 22(5) the Secretary of State is given a power to add species to or remove species from these lists as the need arises.

This legislation effectively provides populations of native species with protection from damage because of predation, parasitism, competition or some other interspecific interaction, for example hybridization with an introduced species, and is similar to provisions to be found in the domestic law of most, if not all, countries.

\section{Problems with definitions: what is a native species?}

Definitions are extremely important in establishing the intention of the law. Nechay (1996) has drawn attention to the importance of distinguishing between the reintroduction, restocking, reinforcement, translocation and introduction of species. He notes that the term 'reintroduction' is often used in practice to describe the release of animals in order to enhance their existing populations; a process that he prefers to call 'restocking' or 'reinforcement'. Nechay also emphasizes that the term 'reintroduction' should not be used where a species is placed in an ecosystem where it has not previously existed, as in these circumstances the term 'introduction' is more precise. He concludes that whether a species is the subject of introduction, reintroduction or reinforcement may have serious implications for its future for a number of reasons, including the uncontrolled transfer of genes from one area to another and the possible spread of disease.

The World Conservation Union (IUCN) defines reintroduction as:

An attempt to establish a species in an area which was once part of its historical range, but from which it has been extirpated or become extinct (IUCN, 1995). 
Neither the term 'native species' nor the expression 'native to their territory' are defined in the Berne Convention, the Habitats Directive or the Birds Directive, yet the definition of these terms is critical to the interpretation of the law. The Biodiversity Treaty does not use the terms 'native' or 'non-native species', the latter term being replaced by the term 'alien species', but without any definition. In the absence of clear definitions of these terms, parties to these agreements appear to be free to interpret them as they see fit. Such an approach is likely to lead to inconsistency between states because the intention of the law is unclear.

Annex IV of the Habitats Directive lists 'Animal and Plant Species of Community Interest in Need of Strict Protection', including the wild cat Felis silvestris, the otter Lutra lutra, the beaver Castor fiber, the wolf Canis lupus, two species of lynx Lynx lynx and L. pardina, and the brown bear Ursus arctos. An important practical point that arises as a result of the listing of species in the Directive is that not all species of European Community interest currently occur in Britain, although their ranges may have extended into Britain in the past. The Directive does not indicate how far back in time a Member State should look in order to establish whether or not a particular species is to be considered 'native to their territory'.

How far should we go in attempting to reintroduce locally extinct species? The limestone caves of Derbyshire contain layers of clay and rubble that hold evidence of a once rich mammalian fauna. Bison, reindeer, wolf, lynx and the brown bear once roamed the Peak District (Pigott, 1975). Reindeer were still present in Scotland in the 10th century and were then reintroduced in the 17th century, again in 1820 and then once again in 1951. The brown bear survived in England to c. 1000 and in Wales and Scotland to c. 1057. There were still beavers in Wales and Scotland 500 years ago and wolves survived in Scotland until 1743 (Fisher, 1970). If we interpret Article 22(a) as referring to any species that has been native in the recent past (say the last few hundred years), the Directive could be interpreted as requiring that we examine the feasibility of reintroducing wolves, lynx and even bears. Furthermore, many species that most people would undoubtedly consider native to Britain were originally introduced. The best known example is the rabbit Oryctolagus cuniculus. How long must a species have been established in a Member State before it is considered native? If the population of a long-established introduced species declines, are we legally obliged to consider repopulation? Such considerations depend on the definition of 'native species'.

Another legal dilemma arises as the result of the obligation to prevent the introduction of unwanted non- native species. The Habitats Directive requires the careful regulation of the introduction of non-native species and requires that such introductions be prohibited if they prejudice natural habitats, or wild native fauna and flora (Article 22(b)) as required by the Berne Convention (Article 11(2)b).

Under Article 11 of the Birds Directive, Member States are required to:

... see that any introduction of species of bird which does not occur naturally in the wild state in the European territory of the Member States does not prejudice the local flora and fauna.

It does not refer to the possible need to prohibit introductions, and appears not to restrict introduction of non-native species into the territory of a Member State as long as the species occurs in the wild state somewhere within the territory of the Community. There would seem to be no requirement under this article to consider the possible damage that might be done to the environment if, for example, flamingos from Spain were introduced into Britain. However, the provisions of the Habitats Directive (Article 22(b)) that refer to the reintroduction of species apply to birds as much as to any other species.

The definition of a 'native species' is clearly critical here in determining whether a Member State should be encouraging the reintroduction of a species or prohibiting it. Are wolves native to Britain or not? If we use a narrow interpretation of 'native' it could be argued that once a species becomes extinct in a Member State it should no longer be considered native and its reintroduction must be regulated, and may even be prohibited if considered undesirable. If we use a wider interpretation we leave ourselves open to at least considering the reintroduction of many species that have been absent for a considerable period. Should we seek only to protect species that are extant in a particular Member State from becoming extinct in that State (by intrastate translocation of specimens), or should we be re-establishing species that have become extinct within that Member State (by interstate translocations)?

\section{How should we decide whether or not to undertake a reintroduction?}

How far back in time should we look for historical evidence of the former natural occurrence of a species? One approach to this problem would be to draw a line in time and not to consider the reintroduction of any species that disappeared before that point. If this line were to be drawn at say 200 years it would prevent attempts to establish wolves in Scotland, but it might also prevent the re-establishment of 
less controversial species, such as beaver, which died out much earlier.

The same dilemma exists in relation to introduced species. Should we be seeking to eradicate the rabbits that were introduced by the Normans and the hares Lepus europaeus that were brought to Britain by the Romans? Should we be eradicating non-native trees such as sycamore Acer pseudoplatanus and Norway spruce Picea abies?

It is too simplistic to use time alone as a criterion for establishing whether or not a species should be considered native to a region. Some species have disappeared as a result of human activity, and a strong case could therefore be made for their reintroduction, for example wolves in England. Others have disappeared because of climate or other environmental changes that may have resulted in the complete loss of suitable habitats. In such circumstances, assuming that suitable source populations of the species still exist, it would be more difficult to justify reintroduction.

Recommendation Number R (85) 15 (1985) of the Council of Europe Committee of Ministers to Member States on the reintroduction of species lays down criteria for responsible reintroductions. It recommends that governments of Member States:

1. Carry out reintroduction projects only after conducting research to:

(a) determine the causes of extinction;

(b) analyse past and present ecological characteristics of the area concerned;

(c) propose remedies for the causes of extinction;

(d) enumerate management measures to be taken before, during and after the reintroduction;

(e) evaluate the chances of success and possible repercussions of reintroduction;

(f) establish which subspecies or ecotypes are the closest to those that are extinct or are best suited to the reintroduction area.

2. Authorize reintroduction only after remedying the causes of extinction and restoring biotopes where necessary.

3. Prohibit reintroduction where adverse effects on the ecosystem are feared.

4. Inform the local population and interested groups of the reintroduction project.

5. Prohibit collecting from a population where this would constitute a threat to it.

6. Limit the duration of reintroduction projects and, if unsuccessful, give up further attempts.

7. Ensure scientific support, supervision and documentation until the reintroduced individuals are integrated into the local biological community.

8. Inform the European Committee for Conservation of Nature and Natural Resources, and if necessary the governments of neighbouring countries, of reintroduction projects and, if possible, co-ordinate reintroductions among the countries concerned.

This Recommendation is not legally binding because the Committee of Ministers does not possess the binding powers, legislative competence or enforcement mechanisms available to the EU. Nevertheless it may be considered 'soft law', such instruments being widely used in the rapidly developing and uncertain field of international environmental law (Birnie \& Boyle, 1992). The Council of Europe has a much wider political base than the EU, with 41 Member States, and it accords consultative status to over 200 NGOs. Its Recommendations may, therefore, represent a wider consensus view than those expressed in EU law.

Clear scientific and legal guidance on the conduct of reintroduction programmes is essential. In 1988 the IUCN established a Reintroduction Specialist Group to encourage responsible reintroductions. It maintains a database of over 400 reintroductions in over 80 countries (Stanley Price et al., 1996) but has estimated that only 11 per cent of all reintroductions could be considered successful. In 1992 the Standing Committee of the Berne Convention established a group of experts on the legal aspects of introduction and reintroduction of wildlife species (Déjeant-Pons, 1996). It is important to the success of future reintroduction programmes that the scientific agencies that are responsible for the implementation of these programmes co-operate with the legislators who produce the legal framework within which they operate.

The existence of guidelines may be critical in persuading governments to co-operate in reintroduction projects. In their recent study of the feasibility of reintroducing the golden eagle Aquila chrysaetos into the Republic of Ireland, O'Toole et al. (in press) discussed in detail how their proposal satisfied the legal requirements of the National Park and Wildlife Service and Department of Agriculture of the Republic, Scottish Natural Heritage (the donor country) and the release criteria of Recommendation R (85) 15. The authors also described how they proposed to overcome the frequent short-comings of other reintroduction projects, identified by Fischer \& Lindenmayer (2000) and Cade (2000), including failures to justify the reintroduction, inadequate monitoring and lack of clear definitions of success. In contrast, a recent (theoretical) consideration of the feasibility of reintroducing wild boar Sus scrofa to Scotland (Leaper et al., 1999) made an unconvincing legal argument for reintroduction. Acknowledging that the species was not an Annex IV species under the Habitats Directive (and as such Member States were not required to consider reintroduction under Article 22) the authors failed to consider any of the relevant inter- 
national law, referring only to an out-of-date IUCN Position Statement (IUCN, 1987).

In May 1995 the Council of the World Conservation Union approved Guidelines for Reintroductions (IUCN, 1995) in response to the increasing occurrence of reintroduction projects worldwide. These guidelines updated the World Conservation Union's Position Statement on the Translocation of Living Organisms (IUCN, 1987).

In a further development in 1995, the Council of Europe adopted the Pan-European Biological and Landscape Diversity Strategy (Sofia, October 1995), which stresses the importance of joint efforts for reintroduction and restoration programmes across Europe (Action Theme 11: Action for threatened species, paragraph 11.2):

Mobilize joint efforts, including zoological and botanic gardens expertise throughout Europe, for in situ and $e x$ situ conservation and reintroduction/restoration programmes wherever such actions are integrated into species action plans (1995-2000).

A number of zoos in the United Kingdom are actively engaged in native species breeding and reintroduction schemes in partnership with other conservation organizations. For example, Chester Zoo operates programmes for the restoration of the harvest mouse Micromys minutus, in collaboration with the Cheshire Wildlife Trust, and the sand lizard Lacerta agilis, in partnership with English Nature. The zoo has also released around a hundred barn owls Tyto alba into the local population (Anon., 1999).

\section{The return of the beaver?}

In reintroducing species we need to ask what it is that we seek to re-establish. We cannot completely recreate ecosystems that existed in the past, so is there any point in putting back just some of the extinct species? If beavers were part of a community, which also contained bears, wild boars and wolves, is there any point in reintroducing only beavers? Beavers have not been seen in England since the 12th century and the last beaver sighting in Scotland was in 1527 near Loch Ness (Macdonald, 1995). Now there are plans for its return.

The Mammal Society has recently given its support to the proposed reintroduction of beavers in Scotland. Gorman \& Kruuk (1998) have argued that the beaver should be reintroduced into Scotland because Britain is one of the few countries in the original geographical range of the species in Europe that is currently without beavers. But do the people of Scotland want beavers?

Scottish Natural Heritage has undertaken an extensive public consultation exercise in order to establish public opinion in relation to the reintroduction of the
European beaver to the wild in Scotland (Anon., 1998a). Almost two-thirds (63 per cent) of the 2141 members of the public consulted were in favour of the reintroduction with just 12 per cent against (although many of these gave 'lack of interest' as their reason). A further 1944 responses were received from a 'pro-active public' sample consisting of academics, ecologists, zoologists, conservationists, hillwalkers, and others with similar interests, including land managers. Overall, 86 per cent of this sample favoured reintroduction but the survey identified a clear lack of support from those with a fishing or agricultural interest. In 2001, Scottish Natural Heritage will assess a proposed pilot reintroduction, of around a dozen beavers, supported by a management plan (Anon., 2000).

Favourable responses from public consultation exercises cannot guarantee the success of a species reintroduction programme, assuming it is ecologically sound, because a relatively small proportion of the human population is capable of having a disproportionately large effect. An example of this effect can be found in the United States where the reintroduction of wolves has resulted in a long legal battle between conservationists and ranchers.

\section{A lesson from America - more problems with definitions}

In a federal court ruling in December 1997 Downes J. declared that a programme to reintroduce wolves Canis lupus to Yellowstone National Park and central Idaho was illegal (Wyoming Farm Bureau Federation v Babbitt, 1997). He ordered that the wolves should be removed, but this order was stayed pending an appeal by conservation organizations. The judge found that assigning the translocated wolves experimental and nonessential' status could potentially harm wolves that may naturally migrate from Montana and Canada into the recovery areas, thereby losing their protection under the Endangered Species Act 1973 (ESA).

The case was brought by the Idaho, Montana and Wyoming Farms Bureaus against the Department of the Interior (which oversees the endangered species restoration programmes managed by the Fish and Wildlife Service (FWS)). In spite of the existence of a Wolf Compensation Fund set up by the organization Defenders of Wildlife that compensates ranchers at full market value for verifiable livestock losses, the ranching community is determined to have the wolves removed.

Under the ESA wolves cannot be killed legally in the US. Conferring 'experimental status' on the translocated wolves under section 10(j) of the ESA allowed ranchers legally to kill any wolves found taking livestock on private land. The judge decided, however, that the effect 
of assigning these wolves 'experimental status' was to make the introductions illegal under the ESA because they were introduced within the range of non-experimental (native) populations.

In a second case, brought by the National Audubon Society, attempts have been made to force the FWS to restore full ESA protection to Idaho's wolves, claiming that when experimental animals and endangered populations overlap, the 'experimental' animals revert to 'endangered'.

The American experience with wolf reintroduction programmes shows us the importance of clear legal definitions. The ESA extends the debate on reintroductions by creating a category of animals that are deemed to be 'non-essential experimental populations' within a protected native species. The translocated wolves came originally from Canada. The species was virtually exterminated from the lower 48 states of the US by an intensive government-funded predator-eradication programme in the early decades of the twentieth century. The species has therefore only been absent from the recovery areas for less than 100 years. By any sensible definition the introduced wolves were native species, and their classification as 'experimental' was only instituted to allow ranchers to protect their livestock. If there had been no public objections to the reintroductions these wolves would undoubtedly have been classified as endangered (native) species.

Eventually common sense prevailed. In January 2000, after a long legal battle, the 10th Circuit Court of Appeals overturned the original 1997 decision and determined that an overly technical interpretation of the ESA was inappropriate (Wyoming Farm Bureau Federation $v$ Babbitt 01/13/2000). The wolves have been allowed to stay and are now an important tourist attraction. From 1995 to the end of 1999 approximately 50,000 visitors observed the Druid Peak pack in Lamar Valley, Yellowstone National Park, making them arguably the most viewed wolf pack in the world (Smith et al., 1999).

Wolves have not been the only controversial species in the United States as far as reintroductions are concerned. The FWS received a further blow to its reintroduction programme (Servheen et al., 1995) when ranchers opposed plans to reintroduce grizzly bears Ursus arctos to wilderness areas in central Idaho and Western Montana (Anon., 1998b). Many people perceived the bears as a threat to livestock and the recreational use of the land. The project was also opposed by the Idaho Fish and Game Commission (Anon., 1997). Seven public hearings were held and a 5-month public comment period drew more than 24,000 comments. Lawyers who fought to establish wolf populations in the Rockies believe that the appeal court decision will help them to overcome opposition to the reintroduction of bears and other native species.

A determined government should be able to find a means of ensuring the success of a reintroduction programme even if there is some economic loss as a result. In Norway the government is attempting to establish up to 10 wolf packs in spite of opposition by farmers. During the last 5 years the wolf population of the French Alps has grown steadily. In 1997, the French Environment Ministry paid compensation for more than 800 wolf attacks on sheep. As a result of mounting protests from farmers the French Government has provided funds for them to buy, feed and train Pyrenean mountain dogs (patous) to protect their flocks, rather than resort to wolf-culls (MacIntyre, 1997).

From the point of view of fulfilling a legal obligation, the standard by which we should judge the merits of a reintroduction programme are whether or not it contributes to the conservation of a species or promotes its recovery. The US wolf recovery programme clearly aims to re-establish a typical, and once widespread, North American predator that has been ruthlessly exterminated over most of its former range. The conservation arguments for the return of this species are overwhelming in view of its native status and historically recent decline. Doremus (1997) has discussed the conflict between science and policy in the United States when making listing decisions under the ESA and the legal difficulties encountered when restoring endangered species to the wild (Doremus, 1999, 2000).

\section{Conclusion}

Since 1979 there has been a clear obligation under international law for European States to reintroduce native species. This obligation was extended to the Parties to the Biodiversity Treaty in 1992 and there is some evidence that national laws are beginning to reflect these obligations (Stanley Price et al., 1996).

If our legal obligations to reintroduce species are to be fulfilled, domestic courts must both interpret national laws in the light of the international obligations undertaken by governments and carry the majority of the public with them. The American experience with wolves suggests that US law is strong enough to uphold this duty even in the face of considerable opposition. It is to be hoped that the domestic courts of other countries take a similar view in the same circumstances, in which single-interest pressure groups seek to undermine the legitimate conservation efforts of government agencies.

Wherever extirpated species are returned there may be some economic loss to their human neighbours, especially if these species are large carnivores. 
Compensating these losses must surely be part of the price we pay for fulfilling our legal obligations to reintroduce species. Other reintroduced species may, however, bring significant benefits in increased biodiversity and even ecotourism.

The reintroduction process is most likely to succeed where there is overwhelming public support, but there is a need for governments to be clear where they will draw the line. Where predators are reintroduced the law needs to strike a balance between an obligation to reestablish a species and the rights of those who may suffer loss as a result. Conservation authorities need to be clear in their vision of exactly what it is they are seeking to recreate when reintroducing species to their former habitats. While policy makers will find little to help them in this task in the texts of existing wildlife law, those who seek to promote the cause of threatened species by using reintroduction projects should use the legal system and the commitments made by their governments to validate their efforts.

\section{Postscript}

Since this paper was written Norway has been culling its wolf population and, in the UK, the Countryside and Rights of Way Act 2000 s74(3) appears to have imposed a duty on the governments of England and Wales to restore or enhance, as far as reasonably possible, those priority species listed in the UK Biodiversity Action Plan.

\section{Acknowledgements}

I am grateful to Dr Alan Fielding (Manchester Metropolitan University) who kindly allowed me to read an early version of his paper on the reintroduction of the Golden Eagle prior to publication, and to two anonymous referees who commented on the first draft of this paper and suggested a number of improvements.

\section{References}

Anon. (1997) Fish and Game Commission Policy Paper: Grizzly Bear Recovery. 8 May 1997. Idaho Fish and Game Commission.

Anon. (1998a) Re-introduction of the European Beaver to Scotland: Results of a Public Consultation. Scottish Natural Heritage Research Survey and Monitoring Series No 121, Scott Porter Research and Marketing.

Anon. (1998b) Grizzly bear re-introduction debated. Oryx 32, 27. Anon. (1999) 1999 Zoo Review. Annual Report of the North of England Zoological Society 1999. North of England Zoological Society, Upton-by-Chester, Cheshire, UK.

Anon. (2000) Operational Plan 2000/2001. Scottish Natural Heritage. Scottish Natural Heritage, Edinburgh.

Birnie, P.W. \& Boyle, A.E. (1992) International Law and the Environment. Clarendon Press, Oxford.
Cade, T.J. (2000) Progress in translocation of diurnal raptors. In Raptors at Risk (eds R. D. Chancellor \& B. U. Meyburg), pp. 343-372. WWGBP/Hancock House.

Déjeant-Pons, M. (1996) International legal aspects. Naturopa, 82, 11-12.

Doremus, H.D. (1997) Listing decisions under the Endangered Species Act: why better science isn't always better policy. Washington University Law Quartely, 75, 1029.

Doremus, H.D. (1999) Restoring endangered species: the importance of being wild. Harvard Environmental Law Review, 23, 1 .

Doremus, H.D. (2000) Delisting endangered species: an aspirational goal, not a realistic expectation. Environmental Law Report, 30, 10434.

Fischer, J. \& Lindenmayer, D.B. (2000) An assessment of the published results of animal relocations. Biological Conservation, 96, 1-11.

Fisher, J. (1970) Wildlife Crisis. Hamish Hamilton Ltd., London. Gorman, M. \& Kruuk, H. (1998) Re-introduction of the European Beaver in Scotland. The Mammal Society Statement. Mammal News, Autumn 1998, 115, 6.

IUCN (1987) The IUCN Position Statement on the Translocation of Living Organisms: Introductions, Reintroductions and Restocking. International Union for the Conservation of Nature and Natural Resources, Gland.

IUCN (1995) IUCN/SSC Guidelines For Re-Introductions. SSC Re-introduction Specialist Group. http://iucn.org/themes/ $\mathrm{ssc} /$ pubs/policy/reinte.htm, accessed 11 November 2000.

Leaper, R., Massei, G., Gorman, M.L. \& Aspinall, R. (1999) The feasibility of reintroducing wild boar (Sus scrofa) to Scotland. Mammal Review, 29, 239-259.

Lyster, S. (1985) International Wildlife Law. Grotius Publications, Cambridge.

Macdonald, D. (1995) European Mammals. Evolution and Behaviour. Harper Collins Publishers Ltd, London.

MacIntyre, B. (1997) Farmers' friend strikes fear into alpine walkers. The Times, 17 October 1998, 9.

Nechay, G. (1996) Editorial. Naturopa, 82, 3.

O'Toole, L., Fielding, A.H. \& Haworth, P.F. (in press) Re-introduction of the golden eagle Aquila chrysaetos into the Republic of Ireland. Biological Conservation, in press.

Pigott, C.D. (1975) Natural History. In Peak District. National Park Guide No. 3. (ed. P. Monkhouse), 2nd edn, pp. 13-20. HMSO, London.

Servheen, C., Kasworm, W.F. \& Their, T.J. (1995) Transplanting grizzly bears Ursus arctos horribilis as a management tool results from the Cabinet Mountains, Montana, USA. Biological Conservation, 71, 261-268.

Smith, D.W., Murphy, K.M. \& Guernsey, D.S. (1999) Yellowstone Wolf Project Annual Report 1999. National Park Service. Yellowstone Center for Resources, Yellowstone National Park, Wyoming, USA.

Stanley Price, M.R., Falcon, A. \& Soorae, P.S. (1996) Scientific aspects. Why and how? Naturopa, 82, 4-5.

\section{Legislation cited}

\section{UK law}

Wildlife and Countryside Act 1981 Chapter 69. 
US law

Endangered Species Act 1973.

\section{International and European law}

Convention on Biological Diversity. United Nations (1992) International Environmental Law - Multilateral Treaties, p. $992: 4201 / 043$.

Convention on the Conservation of European Wildlife and Natural Habitats (1979) Council of Europe. European Treaty Series, no. 104

Council Directive 79/409/EEC of 2 April 1979 on the Conservation of Wild Birds (1979). European Union Council. Official Journal of the European Communities, L103 (25.04.79), 1-18.

Council Directive 92/43/EEC of 21 May 1992 on the Conservation of Natural Habitats and Wildfauna and Flora (1992) European Union Council. Official Journal of the European Communities, L206 (22.07.92), 7-39.

Protocol Concerning Specially Protected Areas and Biodiversity in the Mediterranean (adopted in Barcelona on, 10 June, 1995). www.ecolex.org/TR/TR/details/EN003142.htm, accessed 22 December 2000.

Protocol for the Implementation of the Alpine Convention in the Field of Nature Protection and Landscape Conservation (adopted in Chambéry on, 20 December 1994). www.
ecolex.org/TR/TR/details/EN003134.htm, accessed

22 December 2000

Recommendation no. R (85) 15 on the re-introduction of wildlife species (1985). Council of Europe, Committee of Ministers.

\section{Case law}

Wyoming Farm Bureau Federation v Babbitt 01/13/2000 (2000) Appeals from US District Court for the District of Wyoming (DC, No. 94-CV-286).

Wyoming Farm Bureau Federation v Babbitt (1997) 987 F Suppl. 1349, 1372-76 (District of Wyoming).

\section{Biographical sketch}

Dr Paul Rees is a lecturer in the School of Environment and Life Sciences at Salford University, and was formerly a senior lecturer in ecology at Sokoto State College of Education, Nigeria. He received his $\mathrm{PhD}$, for research on the ecology and behaviour of feral cats, in 1982, and holds an LLM in environmental law. Dr Rees is a research associate at Chester Zoo and is currently studying the reproductive behaviour of captive Asian elephants. His other research interests include wildlife and nature conservation law. 